\title{
Measuring behavior patterns and evaluating time-sampling methodology to characterize brush use in weaned beef cattle
}

\author{
K. C. Horvath, ${ }^{1} \odot$ R. L. Toaff-Rosenstein, ${ }^{2,3} \odot$ C. B. Tucker, ${ }^{3 *} \odot$ and E. K. Miller-Cushon ${ }^{1} \oplus$ \\ ${ }^{1}$ Department of Animal Sciences, University of Florida, Gainesville 32611 \\ ${ }^{2}$ Antelliq Innovation Center, Netanya, Israel 4250553 \\ ${ }^{3}$ Center for Animal Welfare, Department of Animal Science, University of California, Davis 95616
}

\section{ABSTRACT}

With growing interest in provision of brushes for cattle and the implications of brush use for behavioral development and welfare, there is a need to validate methodology for quantifying grooming behavior. Our objectives were to characterize patterns of brush use, including bouts, diurnal activity, and individual variability over 24 -h periods, and to validate time-sampling methodologies to characterize these traits, including instantaneous recording at various time intervals and continuous recording for subsets of the day. Data sets from previous experiments involving steers (experiment $1 ; \mathrm{n}=18$ ) and heifers (experiment $2 ; \mathrm{n}=64$ ), consisting of start and end times of brush use continuously recorded from video, were used to analyze brush use. We extrapolated data sets representative of a range of instantaneous recording intervals and compared daily brush duration and bout characteristics with corresponding values from continuous recording using linear regression. To assess validity of sampling subsets of the day, we selected 2 -h time periods representative of different functional parts of the day and compared hourly brush rates with continuous data using Spearman's rank order correlation $\left(r_{\mathrm{s}}\right)$. Brush use was variable among individuals. All steers used the brush in experiment 1 , but $17 \%$ ( $\mathrm{n}=11$ of 64 ) of heifers in experiment 2 did not. Bout analysis revealed that individuals used the brush for an average of 7 to 8 brush bouts lasting 4 to $6 \mathrm{~min}$, leading to an average of 24 and $36 \mathrm{~min} / \mathrm{d}$ for experiments 1 and 2, respectively. Cattle used the brush mainly during daylight hours, with peaks around sunrise, sunset, and the afternoon. Instantaneous recording at intervals less than 1 to $3 \mathrm{~min}$, depending on the experiment, provided good estimates of daily brush use duration $\left(\mathrm{R}^{2}>0.95\right.$ and slope and intercept not different from 1 and 0 , respectively), but intervals

Received February 24, 2020.

Accepted April 28, 2020.

*Corresponding author: cbtucker@ucdavis.edu
$>3$ min were less reliable. For bout characteristics, the intercept of the modeled line differed from 0 for most recording intervals for both experiments, and the slope differed from 1 for recording intervals $>30$ $\mathrm{s}$ in experiment 1, suggesting that time sampling may have underestimated true values. Of the 2 -h periods compared with $24 \mathrm{~h}$ of observation, 1800 to $2000 \mathrm{~h}$ was most highly correlated $\left(\mathrm{r}_{\mathrm{s}}=0.84\right)$ for experiment 1 , and 1800 to $2000 \mathrm{~h}$ and 1400 to $1600 \mathrm{~h}$ were the most highly correlated $\left(\mathrm{r}_{\mathrm{s}}=0.71\right.$ and 0.74 , respectively) for experiment 2 with daily values. When using time-sampling methods to characterize brush use, we suggest that the recording interval used and time of day observed should be carefully considered, as time sampling at an interval of 1 to 3 min may measure daily brush use duration, but continuous recording may be required to capture bout characteristics.

Key words: brush, behavior, bout criteria, instantaneous sampling

\section{INTRODUCTION}

Cattle exhibit grooming behaviors in natural settings by seeking bushes and objects to rub against in their environment (Simonsen, 1979). Opportunities for grooming may have a range of benefits; grooming behaviors promote hygiene (Rich, 1973) and may be calming, as heart rates decrease during grooming bouts (Sato and Tarumizu, 1993; Laister et al., 2011). The expression of grooming is also influenced by a variety of factors, potentially reflecting animal welfare. Grooming changes with the internal state of the animal; for example, it is reduced when animals are sick (Borderas et al., 2008; Hixson et al., 2018). External factors, such as the type of bedding provided (Panivivat et al., 2004), can also affect these behaviors.

Grooming can be facilitated through provision of mechanical brushes, which are quickly adopted and frequently used by dairy cows (Georg and Totschek, 2001; DeVries et al., 2007) and beef heifers (Wilson et al., 2002). Use of a mechanical brush may act as an 
outlet for natural grooming behavior and can stimulate increased self-grooming behavior in group-housed dairy calves (Horvath and Miller-Cushon, 2019). Mechanical brushes allow cows to scratch all areas of their body (DeVries et al., 2007), although preferred areas for use varies by animal (Toaff-Rosenstein et al., 2017). There is some evidence that access to a brush is positive for cows. For example, dairy cows with access to a brush will spend more time grooming their calf after parturition (Newby et al., 2013), potentially due to increased oxytocin release after being stroked (Stock and Uvnäs-Moberg, 1988), which in turn plays a role in pair-bonding (Uvnäs-Moberg, 1996).

Brush use is increasingly studied as a potential metric for detecting and assessing health. Cows are highly motivated to access brushes (McConnachie et al., 2018; Moncada et al., 2020), but use may be reduced because of lethargy associated with inflammation or competing, higher priority activities. For example, dairy cows will decrease use when the brushes are further away and it is hot (Mandel et al., 2013) or when cows are lame (Mandel et al., 2018) or metritic (Mandel et al., 2017). However, the effect of illness is not entirely consistent. In one study, crossbred beef steers with respiratory disease used stationary brushes less than healthy controls (Toaff-Rosenstein et al., 2016b), but this pattern was not replicated in a subsequent experiment with mechanical brushes (Toaff-Rosenstein et al., 2016a).

Due to the increasing use of brushes on farms and in scientific studies, and the implications of brush use for animal welfare, the methodology used to collect brush use information requires scrutiny. Across the literature, brush use is typically described as total daily brush use duration, percentages of time during observation periods, or assessed through various time-sampling techniques, which may not capture representative durations of use or the bout structure across the day. Some studies also aim to capture lack of brush use to detect potential problems (Mandel et al., 2013, 2017, 2018). However, the validity of time-sampling methodologies and duration and timing of observation periods for characterizing brush use have not been well defined. In addition to measuring daily brush use duration, it may also be important to capture frequency of brush use. In many cases, behavior bout characteristics may be more responsive to environmental or management factors than total daily duration of behavior [e.g., changes in meal patterns but not feeding time in response to competition (Miller-Cushon et al., 2014) or effects of pain relief on lying bout characteristics (Winder et al., 2017)]. Whereas some studies describe frequency of visits to the brush, use may be best characterized in terms of behavior bouts, as the use of the brush is typically clumped in time and can be modeled to determine objective bout criteria (Horvath and MillerCushon, 2019).

Therefore, the objectives of this study were to (1) characterize patterns of brush use, including bout characteristics, diurnal activity, and individual variability, over 24-h periods in weaned beef steers and heifers, as brush use may vary between populations and (2) determine the validity of different time-sampling methodologies, including instantaneous recording at different intervals and continuous recording for subsets of the day, for measuring brush use duration and bout characteristics.

\section{MATERIALS AND METHODS}

\section{Animals and Experimental Design}

Data sets from 2 studies were used to characterize brush use patterns with an automated grooming brush (model \# 91526202 Swinging Cow Brush, DeLaval, Kansas City, MO) in weaned cattle and are publicly available via Dryad (Horvath et al., 2020a). Briefly, experiment 1 (Toaff-Rosenstein et al., 2016a) consisted of data from 40 Angus-Hereford crossbred steers 7 to 10.5 mo of age. Steers were group housed (4/pen and brush) in a barn with concrete floors with straw bedding and 2 solid sides and 2 fenced sides, providing $16.4 \mathrm{~m}^{2}$ /animal. The original study, Toaff-Rosenstein et al. (2016a), involved a challenge model of respiratory disease with data collected from pre- and postchallenge periods in sick and healthy controls. Animals developing spontaneous respiratory disease during the prechallenge period $(\mathrm{n}=13)$ or after start of study (n $=5)$, diarrhea $(\mathrm{n}=1)$, or animals less familiar with the brush in the designated pretrial period $(\mathrm{n}=3)$ were excluded, resulting in a total of 18 individuals in the final analysis in the current experiment 1. Experiment 2 (Toaff-Rosenstein and Tucker, 2018) consisted of data from 80 crossbred beef heifers between 7 and 12 mo of age. Heifers were group housed (8/pen and brush) in enclosed pens with concrete floors with straw bedding, providing $8.3 \mathrm{~m}^{2}$ /animal. In the original study, ToaffRosenstein and Tucker (2018) compared animals that developed spontaneous respiratory disease to those that remained healthy (animals without other conditions which would be expected to alter grooming behavior). The differing objectives of the source data sets resulted in distinct exclusion criteria. In experiment 2 , individuals diagnosed with eye irritation, lameness, tetanus, and aggressive temperament were entirely excluded from analysis $(\mathrm{n}=13)$, and data from an additional 3 heifers were missing for technical reasons (e.g., video camera failure), resulting in a total of 64 . Animals in both studies were checked for symptoms of bovine re- 
spiratory disease according to a modified standardized clinical examination by Collie (1992) performed by veterinarians or trained veterinary students. All findings were scored and recorded on a daily basis. These studies (Toaff-Rosenstein et al., 2016a; Toaff-Rosenstein and Tucker, 2018) were approved by the University of California, Davis Institutional Animal Care and Use Committee.

Eight black and white video cameras (model WVBP334, Panasonic Corporation of North America, Secaucus, NJ) with lenses (model \# 13VG2812ASII, Tamron, Commack, NY) recorded a 24-h period using digital surveillance software (model \# GC-1120/1240/1480; USA Vision Systems Inc., Irvine, CA). Red holiday lights were suspended from the pen's rafters and operated on a timer between 1600 and $8000 \mathrm{~h}$ to allow video to be recorded at night. Behavior was recorded continuously for individuals, with brush use defined as physical contact with the brush bristles while the animal was standing. We recorded that brush use began with initial contact (individual brush use "start times" recorded to the nearest second) and ended (individual brush use "end times") when $\geq 2$-s lapse in contact with the brush occurred (Toaff-Rosenstein and Tucker, 2018). These brush use start and end times were additionally used for analysis of brush use bout characteristics, as described below.

\section{Data Analysis}

The brush use start and end times obtained from continuous recording of each individual animal (for those animals that use the brush: $\mathrm{n}=18$ for experiment 1 and $n=53$ for experiment 2) were converted into 1-s interval data and used to extrapolate data that would have been obtained from the same observation period using instantaneous recording at the following intervals: $5 \mathrm{~s}, 15 \mathrm{~s}, 30 \mathrm{~s}, 1 \mathrm{~min}, 3 \mathrm{~min}, 5 \mathrm{~min}, 10 \mathrm{~min}$, 15 min (using PROC EXPAND and PROC MEANS in SAS v. 9.4, SAS Institute Inc., Cary, NC) following methodology described and supplemental materials provided by Chen et al., 2016). These data were then used to calculate estimates for daily brush use duration.

For continuous data and a subset of recording intervals $(5 \mathrm{~s}, 15 \mathrm{~s}, 30 \mathrm{~s}, 1 \mathrm{~min}$, and $3 \mathrm{~min})$, bout analysis was performed using the start and end times of periods of brush use. For data extrapolated for different recording intervals, start and end times were estimated based on assigning a block of time equal in length to the time-sampling interval to each positive scan. Bout criteria were calculated separately by experiment and by recording interval, based on methodology described previously and supplemental materials provided by
Horvath and Miller-Cushon (2019). Briefly, $\log _{10}$-transformed frequency distributions of intervals between periods using the brush were modeled with 2 normal distributions (using the $\mathrm{R}$ package mixdist; Macdonald and $\mathrm{Du}, 2018$ ). The bout criterion was determined as the point at which the distribution curve corresponding to the shorter intervals intersected the distribution curve corresponding to the longer intervals. Based on our determined bout criteria, bout characteristics for individual animals were calculated for the 24-h observation period: bout frequency (number of intervals between periods of observed behavior that exceeded the criterion), bout time (sum of duration performing the behavior and intervals shorter than the bout criterion), and bout duration (bout time divided by bout frequency).

Daily brush duration and brush use bout characteristics (bout frequency, bout time, and bout duration) determined using different instantaneous recording intervals were compared with corresponding values determined from continuous recording using linear regression (PROC REG; SAS v. 9.4) with the WHITE heterogeneity-consistent covariance matrix estimator (White, 1980) for nonhomoscedastic residual errors. Data were square root transformed to meet assumptions of normality; however, data could not be transformed for 10 and $15 \mathrm{~min}$, preventing analysis of these time samples. Tests for whether slope and intercept differed from 1 and 0 , respectively, were performed and coefficients of determination were generated from these regressions. In evaluating the validity of various recording intervals, we considered whether the coefficient of determination was $\geq 0.9$ and whether slope and intercept differed significantly from 1 and 0 , respectively.

To further assess whether sampling during a subset of the day is representative of 24 -h observations, we extrapolated continuous brush use data to select six 2-h time periods, encompassing sunrise (0500-0700 h), sunset (1800-2000 h), feeding activities (1400-1600 h and $1600-1800 \mathrm{~h}$ for both experiments and $0700-0900 \mathrm{~h}$ for experiment 1 only), and during a time period when human activity was limited and animals were relatively undisturbed (1200-1400 h). The hours 0700 through 0900 were excluded from analysis for experiment 2 because animals were removed from the pen for $<1.5 \mathrm{~h}$ between 0730 and $1130 \mathrm{~h}$. Data for the 2-h observations were calculated as hourly rates (time spent using the brush divided by hour). The average hourly rates based on 2-h observations were compared with hourly averaged data from the full 24 -h observation periods, using Spearman's rank order correlation (PROC CORR in SAS), as these data were not normally distributed and could not be transformed to meet this assumption. 


\section{RESULTS AND DISCUSSION}

\section{Characterizing Daily Brush Use, Bout Characteristics, and Diurnal Patterns}

Brush use was variable among individuals, with some animals using the brush for several hours and some not using it at all (Table 1). All steers used the brush at least briefly in experiment 1 , but $17 \%(\mathrm{n}=11$ of 64$)$ of the heifers in experiment 2 did not use the brush. This individual variability is similar to previously reported brush use in dairy calves (Horvath and Miller-Cushon, 2019). Bout analysis revealed that individuals that used the brush had, on average, 7 brush bouts lasting 4 to $6 \mathrm{~min}$, resulting in an average duration of 24 $\mathrm{min} / \mathrm{d}$ for experiment 1 and $36 \mathrm{~min} / \mathrm{d}$ for experiment 2 spent on brush use activities (Table 1). The majority of individuals had frequent, short bouts, although some individuals had longer bout durations (Figure 1), suggesting that future research should take the wide variation in behavior into account when developing sampling methods, as the reliability of time-sampling methodology may vary with individual expression.

Brush use varied over the course of the day; diurnal patterns of brush use are characterized for both experiments in Figure 2. Cattle used the brush mainly during daylight hours with peaks in use around sunrise, sunset, and throughout the afternoon. For experiment 2 (Figure $2 \mathrm{~b}$ ), heifers also had peaks in brush use activity that coincided with a period of time during when animals were removed for handling and returned to the pen after approximately $1.5 \mathrm{~h} /$ heifer. This suggested that individuals may be more likely to use the brush when they are already active, which typically occurs when moved into or out of a pen for milking (Mat-

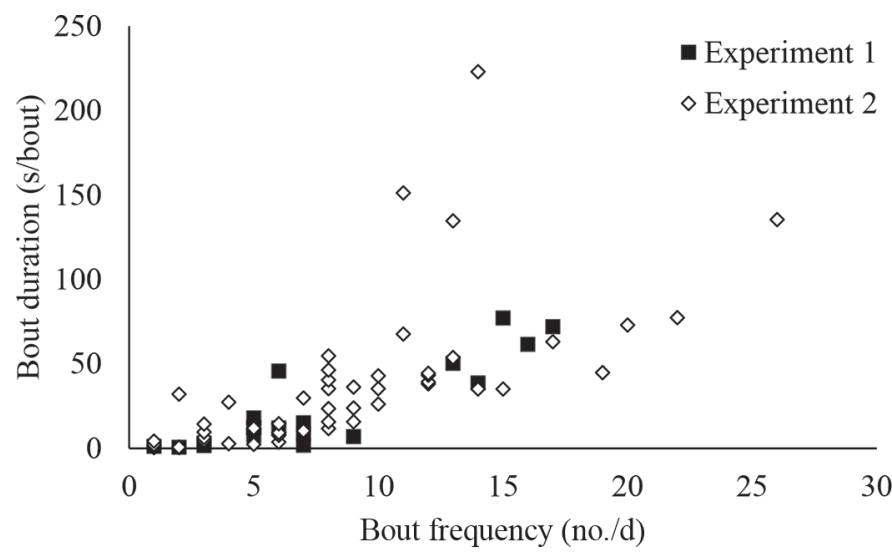

Figure 1. The relationship between mean brush bout duration (s/ bout) and bout frequency (no./d) for animals that used the brush in experiments $1(\mathrm{n}=18)$ and $2(\mathrm{n}=53)$.
Table 1. Brush use characteristics for animals that used the brush in experiments $1(\mathrm{n}=18)$ and $2(\mathrm{n}=53)$

\begin{tabular}{lrccc}
\hline Item & Mean & SE & Minimum & Maximum \\
\hline Experiment 1 & & & & \\
$\quad$ Time (min/d) & 24.1 & 6.2 & 0.5 & 77.1 \\
Bouts (no./d) (min/bout) & 4.1 & 1.2 & 1.0 & 17.0 \\
$\quad$ Bout duration (m/d) & 0.7 & 0.5 & 8.3 \\
$\quad$ Bout time (min/d) & 35.0 & 8.8 & 0.7 & 124.5 \\
Experiment 2 & & & & \\
$\quad$ Time (min/d) & 35.9 & 5.9 & 0.1 & 222.8 \\
Bouts (no./d) (min /bout) & 5.6 & 0.9 & 1.0 & 28.0 \\
Bout duration (mime & 0.8 & 0.1 & 16.9 \\
Bout time (min/d) & 45.2 & 7.1 & 0.1 & 269.9 \\
\hline
\end{tabular}

${ }^{1}$ These data exclude heifers $(\mathrm{n}=11$ of 64 total) that did not use the brush. Inclusion of data from heifers that did not use the brush yield a mean brush use duration of $29.2 \mathrm{~min} / \mathrm{d}(\mathrm{SE}=5.2)$ and bout frequency of 6.5 bouts/d $(\mathrm{SE}=0.8)$.

tachini et al., 2011) or when feeding (Mandel et al., 2013)

Brush use may depend on a wide range of individual and social factors, which have potential to influence frequency and duration of use, as well as the nature of contact with the brush. Individual brush use is likely to be affected by age and stage of production, and corresponding changes in time budgets. For example, DeVries et al. (2007) reported that lactating dairy cows used a mechanical brush for less than $7 \mathrm{~min} / \mathrm{d}$ on average, whereas the present results describing brush use in weaned cattle resemble more closely brush use of a mechanical brush in pre-weaned dairy calves (e.g., $20 \mathrm{~min} / 12$-h observation period; Horvath and MillerCushon, 2019). Social factors are also likely to influence brush use. Expression of other behaviors, including feeding, are subject to factors such as competition at a feed bunk (Val-Laillet et al., 2008) and stocking density (Huzzey et al., 2006), and thus it is likely that similar factors may influence access to a resource such as the brush. Guidelines provided by the DeLaval brush manufacturer state that 1 brush can accommodate 60 cows, which is a much greater stocking density than animals experienced in the present experiments (4-8 individuals/brush). However, effects of stocking density on brush use have not been studied to our knowledge, and we suggest a need for research evaluating changes in brush use with stocking density to provide management guidance. We speculate that social factors, such as resource guarding and dominance hierarchies, may affect brush use.

Anecdotal observation by study personnel suggested that some individuals had their brush use interrupted by being displaced from the brush. We also noted instances of a bystander being briefly touched by the device while another individual made primary use of the brush, suggesting that when cattle are group housed 

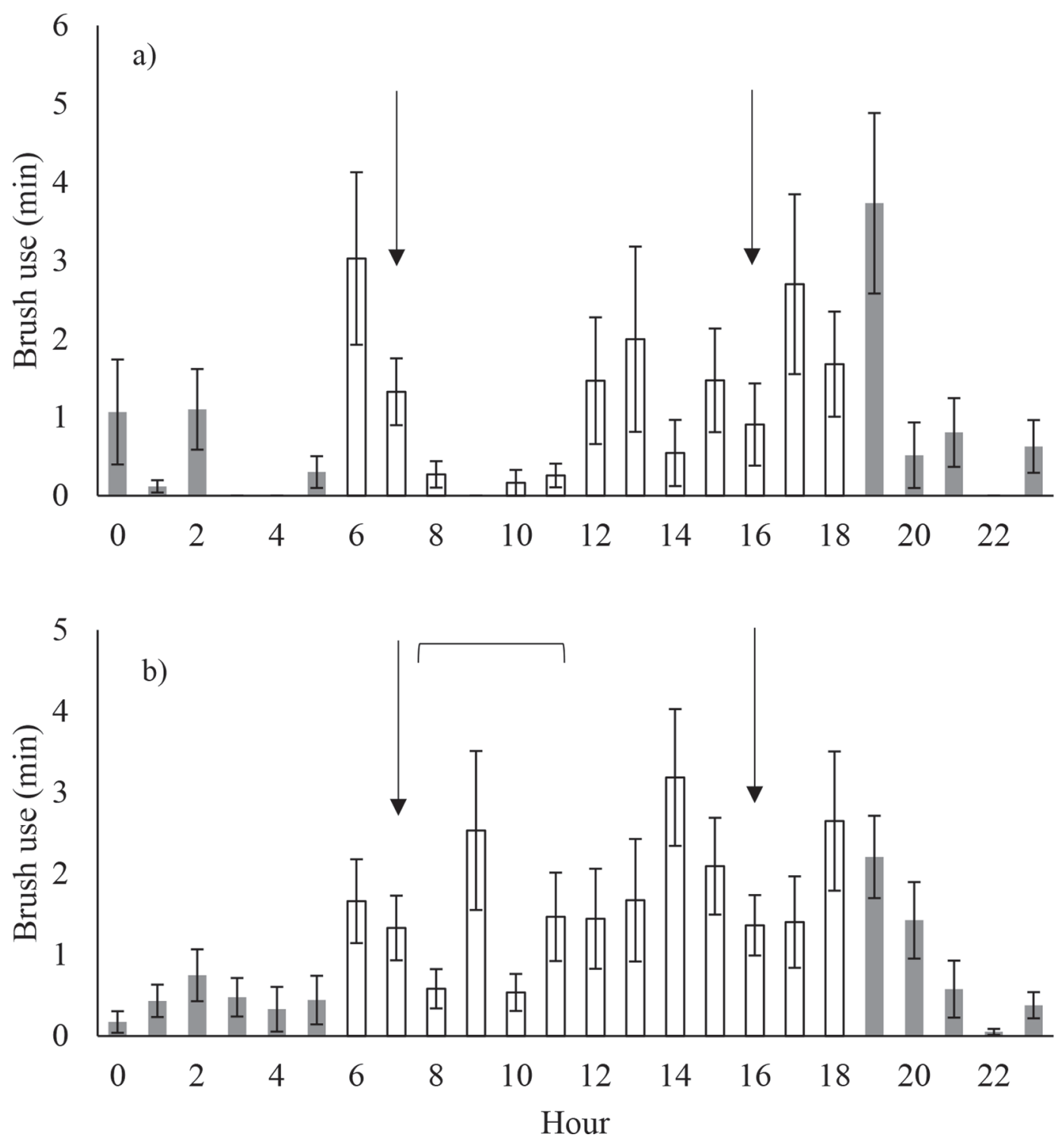

Figure 2. Diurnal patterns of mean hourly brush use for all individuals that used the brush for (a) experiment $1(\mathrm{n}=18)$ and $(\mathrm{b})$ experiment $2(\mathrm{n}=53)$. For experiment 1 , fresh feed was delivered at 0700 to 0730 and 1630 to $1700 \mathrm{~h}$ as indicated by arrows. For experiment 2 , fresh feed was delivered at 0700 and $1600 \mathrm{~h}$ as indicated by arrows, and animals were removed from pens for $<1.25 \mathrm{~h}$ between 0730 and $1130 \mathrm{~h}$ as indicated by the bracket. Open bars indicate daylight hours and filled bars indicate nighttime hours. Error bars indicate SE.

with an automated brush, not all brush use may be intentionally initiated. Additionally, the location of the brush in the pen may influence accessibility. Individuals in both studies were anecdotally noted to congregate around the brush. Other studies have found that the location of the brush in relation to other pen fixtures, such as the feed bunk, can influence the amount of time that individuals use the brush, especially when experiencing disease (Mandel et al., 2013, 2017, 2018). Further, social factors and stocking density surrounding other resources, such as the feed bunk and stalls, may affect cattle time budgets and brush use and warrant further investigation. In future research, we suggest recording more detail about brush use, such as location of brush use on the body (Toaff-Rosenstein et al., 2017) and social use, including who initiated brush use if multiple individuals are involved, and any occurrence of resource guarding or competition. This detailed information may provide evidence of subtler changes in how brush use is affected by a range of factors.

This study focused on use of automated brushes, yet there is also current interest in providing manual brushes for cattle, which may be a cost-effective option on certain farms. Although manual brush options 
are variable and generally less studied, evidence suggests that they are used for less time than automated brushes (e.g., in dairy calves, 4-8 min/12-h period; Pempek et al., 2017; Horvath et al., 2020b). As such, behavior is likely to depend on the nature of the brush provided, and the methodology characterizing brush use for automated brushes may be less applicable for manual brushes.

\section{Validating Time-Sampling Methodologies for Characterizing Brush Use}

Estimates of daily brush use duration based on continuously recorded data and the range of instantaneous recording intervals are reported alongside linear regression results in Table 2. Data obtained from instantaneous recording at intervals $\leq 3 \mathrm{~min}$ provided good estimates of daily brush use duration for experiment $1\left(\mathrm{R}^{2}\right.$ $>0.95$ and slope and intercept not different from 1 and 0 , respectively; Table 2), but for experiment 2, recording intervals $\leq 1$ min were needed to provided estimates where slope and intercept did not differ significantly from 1 and 0 . For instantaneous recording at 5-min intervals, the coefficient of determination remained high, but the slope and intercept differed significant from 1 and 0 for both experiments. Instantaneous recording at intervals greater than 5 min could not be analyzed due to highly skewed data, with estimates of no brush use for many animals and over-estimates for others. For example, at the 15-min recording interval, estimates of $0 \mathrm{~min} / \mathrm{d}$ (no brush use) were generated for $44 \%$ of animals in experiment 1 and $32 \%$ of animals that used the brush in experiment 2 . These results suggested that short recording intervals $(\leq 3 \mathrm{~min})$ are needed to accurately characterize daily duration of brush use, but that there is no clear cutoff value for an appropriate instantaneous recording interval that will be valid for all experiments.

To calculate bout frequency, bout analysis was performed with each data set corresponding to different recording intervals to determine bout criteria. For experiment 1 , brush bout criteria were determined as $251.2 \mathrm{~s}$ for continuous recording, and $125.9,316.2$, $316.2,251.2$, and $1,258.9 \mathrm{~s}$ for 5 -s, 15 -s, 30-s, 1 -min, and 3 -min recording intervals, respectively. For experiment 2 , bout criteria were determined as $158.5 \mathrm{~s}$ for continuous recording and 199.5, 251.2, 251.2, 398.1, and $1,584.9 \mathrm{~s}$ for 5 -s, 15 -s, $30-\mathrm{s}, 1$-min, and 3 -min recording intervals, respectively. Bout frequencies, as determined for different instantaneous recording intervals, are reported alongside linear regression results in Table 3. The linear relationship between bout frequency obtained through instantaneous recording and continuous recording was weaker than for total daily brush use,

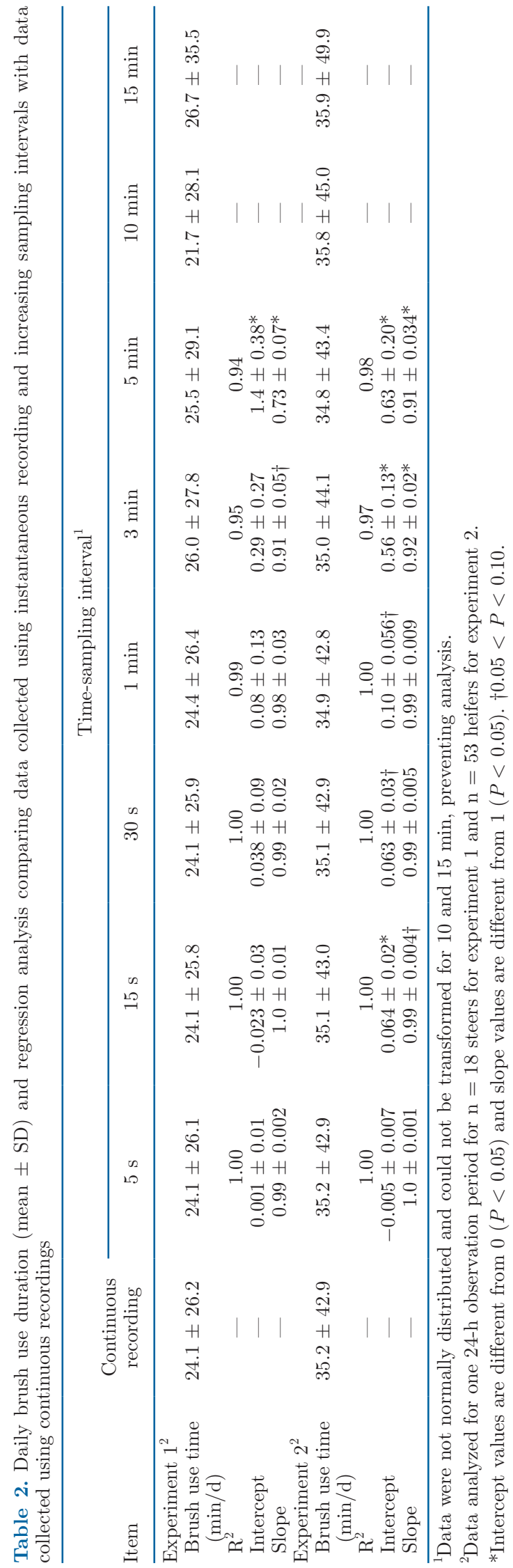


with the intercept of the modeled line differing from 0 for most recording intervals for both experiments, and the slope differing from 1 for recording intervals greater than $30 \mathrm{~s}$ in experiment 1 . As recording interval increased, bout frequency estimates decreased, reflecting the increasing likelihood of missing bouts of brush use with less frequent measurements. In general, when time-sampling methodologies are used, it is understood that the recording interval must be short relative to the typical duration of behavior bouts to adequately characterize the behavior (Martin and Bateson, 2007). Bout characteristics from the present study (as summarized in Table 1) suggest that some bouts of brush use were quite brief (10-30 s). Similar to our findings, instantaneous recording underestimated the number of lying bouts (Ledgerwood et al., 2010) and meals in calves (Miller-Cushon and DeVries, 2011) and the frequency of visiting the water trough and feed bunk in adult cattle (Chen et al., 2016).

An added challenge occurs for characterization of behavior that occurs in bouts, when a bout criterion is needed to calculate bout frequency and duration. In many cases, behavioral bouts are determined based on bout criteria generated from previous studies, but it is also well established that bout criteria depend on bout structure and vary among management settings. For example, in previous work with pre-weaned calves using a rotating brush, we determined the brush use bout criterion to be $125.9 \mathrm{~s}$ (Horvath and Miller-Cushon, 2019), whereas the 2 data sets included in the present study both generated slightly greater bout criteria that differed between experiments ( 251.2 vs. 158.5 from continuous recording; experiments 1 vs. 2). In contrast, bout criteria for use of a stationary brush was estimated to be $13.2 \mathrm{~min}$ in recent work (Horvath et al., 2020b). Assumptions of consistency in bout structure and application of a bout criteria from a previous study has potential to yield unreliable estimates of bout frequency and duration, and we suggest calculation of bout criteria specific to the data set as the most rigorous approach. In this case, it would be necessary to be able to model data sets generated from timesampling approaches to determine a bout criterion, as we have done in the present study. A similar approach was taken by Miller-Cushon and DeVries (2011), with results suggesting that instantaneous recording at 30-s intervals was a valid approach to characterize meal patterns, whereas 5-min intervals were sufficient for determining total daily feeding time. In contrast, in the present study, no instantaneous recording interval provided valid estimates of brush use bout characteristics, suggesting that continuous recording may be necessary in experiments where these data are of interest.

In many cases, it may not be practical to observe animals for 24-h periods; therefore, we explored the association between continuously measured behavior across a full day and samples from 2-h subsets of the day at different time points as a proxy for a full day. Of the 2-h observation periods we compared with 24 -h observation, 1800 to $2000 \mathrm{~h}$ was most highly correlated $\left(r_{\mathrm{s}}=0.84\right)$ for experiment 1 , and 1800 to 2000 and 1400 to 1600 were the most highly correlated $\left(\mathrm{r}_{\mathrm{s}}=\right.$ 0.71 and 0.74 , respectively) for experiment 2 for the total daily brush use (Table 4 ). These 2 -h observation periods corresponded with sunset and the $2 \mathrm{~h}$ before feed was delivered. These data suggest that observing during sunset may provide valid estimates of effects on brush use duration. Similarly, the period of time around sunset has previously been chosen as a time period when researchers observed frequent allogroom-

Table 3. Brush use bout frequency ${ }^{1}$ and regression analysis comparing data collected using instantaneous recording and increasing sampling intervals with data collected using continuous recordings (mean $\pm \mathrm{SD})^{2}$

\begin{tabular}{|c|c|c|c|c|c|c|}
\hline Item & $\begin{array}{l}\text { Continuous } \\
\text { recording }\end{array}$ & \multicolumn{5}{|c|}{ Time-sampling interval } \\
\hline $\mathrm{R}^{2}$ & - & 0.98 & 0.95 & 0.90 & 0.80 & 0.62 \\
\hline Intercept & - & $0.14 \pm 0.07 \dagger$ & $0.32 \pm 0.14^{*}$ & $0.42 \pm 0.18^{*}$ & $1.08 \pm 0.20^{*}$ & $1.38 \pm 0.25^{*}$ \\
\hline Slope & - & $0.91 \pm 0.03^{*}$ & $0.94 \pm 0.05$ & $0.95 \pm 0.07$ & $0.73 \pm 0.08^{*}$ & $0.75 \pm 0.14^{*}$ \\
\hline $\mathrm{R}^{2}$ & - & 0.97 & 0.91 & 0.90 & 0.84 & 0.71 \\
\hline Intercept & - & $0.12 \pm 0.16$ & $0.38 \pm 0.17^{*}$ & $0.45 \pm 0.16^{*}$ & $0.64 \pm 0.17^{*}$ & $1.13 \pm 0.17^{*}$ \\
\hline Slope & - & $1.10 \pm 0.05$ & $0.95 \pm 0.06$ & $0.95 \pm 0.06$ & $0.94 \pm 0.06$ & $0.98 \pm 0.09$ \\
\hline
\end{tabular}

${ }^{1}$ Bout criteria used to calculate bout frequency were determined separately for each data set (continuous recording and all time-sampling intervals).

${ }^{2}$ Data analyzed for one 24-h observation period for $\mathrm{n}=18$ steers for experiment 1 and $\mathrm{n}=53$ heifers for experiment 2 .

*Intercept values are different from $0(P<0.05)$ and slope values are different from $1(P<0.05)$. $\dagger 0.05<P<0.10$. 
Table 4. Hourly mean brush use during 2-h observation periods throughout the day, compared using Spearman's rank order correlation ( $\mathrm{r}_{\mathrm{s}}$ ) with mean hourly brush use based on 24 -h observations (mean $\pm \mathrm{SD}$ )

\begin{tabular}{|c|c|c|c|c|c|c|c|}
\hline Item & 24-h observation & \multicolumn{6}{|c|}{ 2-h observations (time, $\mathrm{h}$ ) } \\
\hline Brush use $(\min / \mathrm{h})$ & $1.00 \pm 1.09$ & $1.32 \pm 2.27$ & $0.80 \pm 0.94$ & $1.73 \pm 3.02$ & $1.01 \pm 1.70$ & $1.80 \pm 3.22$ & $2.71 \pm 2.82$ \\
\hline \multicolumn{2}{|l|}{ Experiment $2^{2}$} & 0.39 & $0.71^{*}$ & $0.56^{*}$ & $0.69^{*}$ & $0.65^{*}$ & $0.84^{*}$ \\
\hline Brush use $(\min / \mathrm{h})$ & $1.47 \pm 1.79$ & $1.31 \pm 2.72$ & - & $1.88 \pm 4.04$ & $3.19 \pm 4.48$ & $1.67 \pm 3.25$ & $2.93 \pm 4.83$ \\
\hline
\end{tabular}

${ }^{1}$ The hours 0700-0900 are excluded from experiment 2 as animals were removed from the pen during this time period.

${ }^{2}$ Data analyzed for one 24 -h observation period for $\mathrm{n}=18$ steers for experiment 1 and $\mathrm{n}=53$ (including only individuals that used the brush) heifers for experiment 2 .

* Spearman's rho values are different from $0(P<0.05)$.

ing behavior in Holstein cattle herds (Sato et al., 1991). However, differing time points throughout the day may better capture responses to environmental factors or even as a means of detecting disease; for example, time spent using a brush upon returning to the pen after milking in dairy cows, around feed delivery, or other daily events may capture subtle responses better than daily summaries of behavior.

Overall, these data revealed considerable variability in brush use among individuals and between experiments, illustrating the importance of validating studyspecific methodology for measuring brush use. In addition, there is a wide range of internal and external factors that may influence expression of brush use and may also affect the validity of various time-sampling methodologies. Validity of time-sampling methods depended on the brush use measurements, with recording intervals of 1 to 3 min capturing total daily brush use in the present data sets, whereas time sampling did not provide valid estimates of bout frequency. It is also important to select relevant times of the day for the study objectives, as not all hours of the day accurately capture daily or hourly rates for brush use but may capture different responses to environmental or management factors. As such, the recording method used to characterize brush use in future research should account for the objectives of the study. We suggest that our approach could provide a framework for validating time-sampling methodology for specific studies. During study preparation, preliminary continuously recorded data may be used to confirm the validity of a timesampling interval.

\section{ACKNOWLEDGMENTS}

Data collection for this project was sponsored by National Research Initiative competitive grant no. 2011-68004-30367 from the USDA National Institute of
Food and Agriculture (Washington, DC). The brushes were donated by DeLaval. This research was supported by the USDA National Institute of Food and Agriculture, Hatch Multistate project NC1029 (Tucker and Miller-Cushon both members). The authors declare no conflicts of interest.

\section{REFERENCES}

Borderas, T. F., A. M. de Passillé, and J. Rushen. 2008. Behavior of dairy calves after a low dose of bacterial endotoxin. J. Anim. Sci. 86:2920-2927. https://doi.org/10.2527/jas.2008-0926.

Chen, J. M., K. E. Schütz, and C. B. Tucker. 2016. Technical note: Comparison of instantaneous sampling and continuous observation of dairy cattle behavior in freestall housing. J. Dairy Sci 99:8341-8346. https://doi.org/10.3168/jds.2016-11351.

Collie, D. D. 1992. Pulmonary function changes and clinical findings associated with chronic respiratory disease in calves. Br. Vet. J. 148:33-40. https://doi.org/10.1016/0007-1935(92)90064-8.

DeVries, T. J., M. Vankova, D. M. Veira, and M. A. G. von Keyserlingk. 2007. Short communication: Usage of mechanical brushes by lactating dairy cows. J. Dairy Sci. 90:2241-2245. https://doi.org/ 10.3168/jds.2006-648.

Georg, H., and K. Totschek. 2001. Investigation of an automatic brush for dairy cows. Cattle Prod. 56:260-261.

Hixson, C. L., P. D. Krawczel, J. M. Caldwell, and E. K. Miller-Cushon. 2018. Behavioral changes in group-housed dairy calves infected with Mannheimia haemolytica. J. Dairy Sci. 101:10351-10360. https://doi.org/10.3168/jds.2018-14832.

Horvath, K. C., and E. K. Miller-Cushon. 2019. Characterizing grooming behavior patterns and the influence of brush access on the behavior of group-housed dairy calves. J. Dairy Sci. 102:3421-3430. https://doi.org/10.3168/jds.2018-15460.

Horvath, K., R. Toaff-Rosenstein, C. Tucker, and E. Miller-Cushon. 2020a. Data from: Measuring behavior patterns and evaluating time sampling methodology to characterize brush use in weaned beef cattle. Dryad https://doi.org/https://doi.org/10.25338/ B8HW4M.

Horvath, K. C., A. N. Allen, and E. K. Miller-Cushon. 2020b. Effects of access to stationary brushes and chopped hay on behavior and performance of individually housed dairy calves. J. Dairy Sci. https://doi.org/10.3168/jds.2019-18042. In press.

Huzzey, J. M., T. J. Devries, P. Valois, and M. A. G. von Keyserlingk. 2006. Stocking density and feed barrier design affect the feeding and social behavior of dairy cattle. J. Dairy Sci. 89:126-133. https: //doi.org/10.3168/jds.S0022-0302(06)72075-6.

Laister, S., B. Stockinger, A. M. Regner, K. Zenger, U. Knierim, and C. Winckler. 2011. Social licking in dairy cattle -Effects on heart 
rate in performers and receivers. Appl. Anim. Behav. Sci. 130:8190. https://doi.org/10.1016/j.applanim.2010.12.003.

Ledgerwood, D. N., C. Winckler, and C. B. Tucker. 2010. Evaluation of data loggers, sampling intervals, and editing techniques for measuring the lying behavior of dairy cattle. J. Dairy Sci. 93:51295139. https://doi.org/10.3168/jds.2009-2945.

Macdonald, P., and J. Du. 2018. mixdist: Finite Mixture Distribution Models. R package version 0.5-5. Accessed Jun. 11, 2018. https:// CRAN.R-project.org $/$ package $=$ mixdist .

Mandel, R., H. Harazy, L. Gygax, C. J. Nicol, A. Ben-David, H. R. Whay, and E. Klement. 2018. Short communication: Detection of lameness in dairy cows using a grooming device. J. Dairy Sci. 101:1511-1517. https://doi.org/10.3168/jds.2017-13207.

Mandel, R., C. J. Nicol, H. R. Whay, and E. Klement. 2017. Short communication: Detection and monitoring of metritis in dairy cows using an automated grooming device. J. Dairy Sci. 100:57245728. https://doi.org/10.3168/jds.2016-12201.

Mandel, R., H. R. Whay, C. J. Nicol, and E. Klement. 2013. The effect of food location, heat load, and intrusive medical procedures on brushing activity in dairy cows. J. Dairy Sci. 96:6506-6513. https: //doi.org/10.3168/jds.2013-6941.

Martin, P., and P. Bateson. 2007. Measuring Behaviour: An Introductory Guide. 3rd ed. Cambridge University Press. Cambridge, UK.

Mattachini, G., E. Riva, and G. Provolo. 2011. The lying and standing activity indices of dairy cows in free-stall housing. Appl. Anim. Behav. Sci. 129:18-27. https://doi.org/10.1016/j.applanim.2010.10 .003 .

McConnachie, E., A. M. C. Smid, A. J. Thompson, D. M. Weary, M. A. Gaworski, and M. A. G. von Keyserlingk. 2018. Cows are highly motivated to access a grooming substrate. Biol. Lett. 14:20180303. https://doi.org/10.1098/rsbl.2018.0303.

Miller-Cushon, E. K., R. Bergeron, K. E. Leslie, G. J. Mason, and T. J. DeVries. 2014. Competition during the milk-feeding stage influences the development of feeding behavior of pair-housed dairy calves. J. Dairy Sci. 97:6450-6462. https://doi.org/10.3168/jds .2014-8065.

Miller-Cushon, E. K., and T. J. DeVries. 2011. Technical note: Validation of methodology for characterization of feeding behavior in dairy calves. J. Dairy Sci. 94:6103-6110. https://doi.org/10.3168/ jds.2011-4589.

Moncada, A. C., H. W. Neave, M. A. G. von Keyserlingk, and D. M. Weary. 2020. Use of a mechanical brush by dairy cows with chorioptic mange. Appl. Anim. Behav. Sci. 223:104925.https://doi.org/ 10.1016/j.applanim.2019.104925.

Newby, N. C., T. F. Duffield, D. L. Pearl, K. E. Leslie, S. J. LeBlanc, and M. A. G. von Keyserlingk. 2013. Short communication: Use of a mechanical brush by Holstein dairy cattle around parturition. J. Dairy Sci. 96:2339-2344. https://doi.org/10.3168/jds.2012-6016.

Panivivat, R., E. B. Kegley, J. A. Pennington, D. W. Kellogg, and S. L. Krumpelman. 2004. Growth performance and health of dairy calves bedded with different types of materials. J. Dairy Sci. 87:3736-3745. https://doi.org/10.3168/jds.S0022-0302(04)73512 -2 .

Pempek, J. A., M. L. Eastridge, and K. L. Proudfoot. 2017. The effect of a furnished individual hutch pre-weaning on calf behavior, response to novelty, and growth. J. Dairy Sci. 100:4807-4817. https: //doi.org/10.3168/jds.2016-12180.

Rich, G. B. 1973. Grooming and yarding of spring-born calves prevent paralysis caused by the Rocky Mountain wood tick. Can. J. Anim. Sci. 53:377-378. https://doi.org/10.4141/cjas73-057.
Sato, S., S. Sako, and A. Maeda. 1991. Social licking patterns in cattle (Bos taurus): Influence of environmental and social factors. Appl. Anim. Behav. Sci. 32:3-12. https://doi.org/10.1016/S0168 $-1591(05) 80158-3$

Sato, S., and K. Tarumizu. 1993. Heart rates before, during and after allo-grooming in cattle (Bos taurus). J. Ethol. 11:149-150. https:/ /doi.org/10.1007/BF02350048.

Simonsen, H. B. 1979. Grooming behaviour of domestic cattle. Nord. Vet. Med. 31:1-5.

Stock, S., and K. Uvnäs-Moberg. 1988. Increased plasma levels of oxytocin in response to afferent electrical stimulation of the sciatic and vagal nerves and in response to touch and pinch in anaesthetized rats. Acta Physiol. Scand. 132:29-34. https://doi.org/10 .1111/j.1748-1716.1988.tb08294.x.

Toaff-Rosenstein, R. L., L. J. Gershwin, and C. B. Tucker. 2016a. Fever, feeding, and grooming behavior around peak clinical signs in bovine respiratory disease. J. Anim. Sci. 94:3918-3932. https://doi .org/10.2527/jas.2016-0346.

Toaff-Rosenstein, R. L., L. J. Gershwin, A. J. Zanella, and C. B. Tucker. 2016b. The sickness response in steers with induced bovine respiratory disease before and after treatment with a non-steroidal anti-inflammatory drug. Appl. Anim. Behav. Sci. 181:49-62. https: //doi.org/10.1016/j.applanim.2016.05.016.

Toaff-Rosenstein, R. L., and C. B. Tucker. 2018. The sickness response at and before clinical diagnosis of spontaneous bovine respiratory disease. Appl. Anim. Behav. Sci. 201:85-92. https://doi.org/10 .1016/j.applanim.2018.01.002.

Toaff-Rosenstein, R. L., M. Velez, and C. B. Tucker. 2017. Technical note: Use of an automated grooming brush by heifers and potential for radiofrequency identification-based measurements of this behavior. J. Dairy Sci. 100:8430-8437. https://doi.org/10.3168/ jds.2017-12984.

Uvnäs-Moberg, K. 1996. Neuroendocrinology of the mother-child interaction. Trends Endocrinol. Metab. 7:126-131. https://doi.org/ 10.1016/1043-2760(96)00036-7.

Val-Laillet, D., D. M. Veira, and M. A. G. von Keyserlingk. 2008. Short communication: Dominance in free-stall-housed dairy cattle is dependent upon resource. J. Dairy Sci. 91:3922-3926. https:// doi.org/10.3168/jds.2008-1332.

White, H. 1980. A heteroskedasticity-consistent covariance matrix estimator and a direct test for heteroskedasticity. Econometrica 48:817-839. https://doi.org/10.2307/1912934.

Wilson, S. C., F. M. Mitlöhner, J. Morrow-Tesch, J. W. Dailey, and J. J. McGlone. 2002. An assessment of several potential enrichment devices for feedlot cattle. Appl. Anim. Behav. Sci. 76:259-265. https://doi.org/10.1016/S0168-1591(02)00019-9.

Winder, C. B., S. J. LeBlanc, D. B. Haley, K. D. Lissemore, M. A. Godkin, and T. F. Duffield. 2017. Clinical trial of local anesthetic protocols for acute pain associated with caustic paste disbudding in dairy calves. J. Dairy Sci. 100:6429-6441. https://doi.org/10 $.3168 /$ jds.2017-12724.

\section{ORCIDS}

K. C. Horvath ๑ https://orcid.org/0000-0002-5345-6509

R. L. Toaff-Rosenstein ( ) https://orcid.org/0000-0003-3353-0908

C. B. Tucker ๑ https://orcid.org/0000-0002-6014-444X

E. K. Miller-Cushon (1) https://orcid.org/0000-0003-1876-807X 